
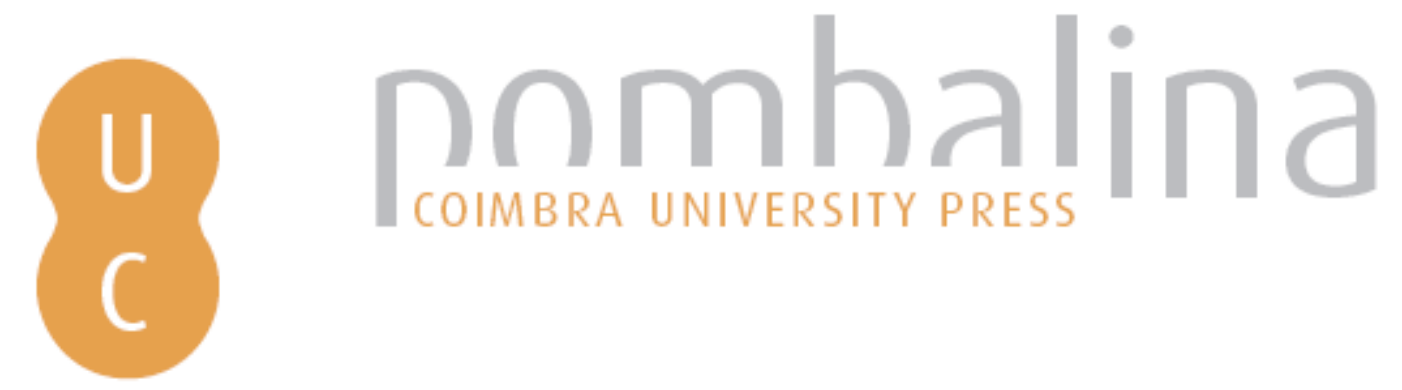

\title{
Urbanismo sustentável em ambiente litorâneo: um projeto de adequação aplicado a zona de expansão da cidade de Aracaju, Sergipe, Brasil
}

Autor(es): $\quad$ Garcia, M. G.; Garcia, G. G.; Garcia, A. J. V.

Publicado por: Imprensa da Universidade de Coimbra

URL

persistente:

URI:http://hdl.handle.net/10316.2/31427

DOI:

DOI:http://dx.doi.org/10.14195/978-989-26-0531-9_9

Accessed : $\quad$ 26-Apr-2023 11:11:50

A navegação consulta e descarregamento dos títulos inseridos nas Bibliotecas Digitais UC Digitalis, UC Pombalina e UC Impactum, pressupõem a aceitação plena e sem reservas dos Termos e Condições de Uso destas Bibliotecas Digitais, disponíveis em https://digitalis.uc.pt/pt-pt/termos.

Conforme exposto nos referidos Termos e Condições de Uso, o descarregamento de títulos de acesso restrito requer uma licença válida de autorização devendo o utilizador aceder ao(s) documento(s) a partir de um endereço de IP da instituição detentora da supramencionada licença.

Ao utilizador é apenas permitido o descarregamento para uso pessoal, pelo que o emprego do(s) título(s) descarregado(s) para outro fim, designadamente comercial, carece de autorização do respetivo autor ou editor da obra.

Na medida em que todas as obras da UC Digitalis se encontram protegidas pelo Código do Direito de Autor e Direitos Conexos e demais legislação aplicável, toda a cópia, parcial ou total, deste documento, nos casos em que é legalmente admitida, deverá conter ou fazer-se acompanhar por este aviso. 



\title{
URBANISMO SUSTENTÁVEL EM AMBIENTE LITORÂNEO: UM PROJETO DE ADEQUAÇÃO APLICADO A ZONA DE EXPANSÁO DA CIDADE DE ARACAJU, SERGIPE, BRASIL
}

\author{
SUSTAINABLE URBANISN IN COASTAL ENVIRONMENT: \\ A PROJECT OF ADJUSTABILITY APPLIED TO AN EXPANSION \\ ZONE OF ARACAJU CITY SERGIPE, BRAZIL
}

M. G. Garcia ${ }^{1}$, G. G. Garcia² \& A. J. V. Garcia ${ }^{3}$

\begin{abstract}
Resumo - Este trabalho apresenta os resultados, do estudo geocientífico e multidisciplinar, que foram aplicados a ambientes litorâneos e a sua utilidade em termos de uma proposta de desenvolvimento urbano sustentável na zona de expansão da cidade de Aracaju, capital do estado de Sergipe, Nordeste do Brasil. Neste estudo são apresentadas sugestôes que podem levar à preservação de ecosistemas costeiros, bem como à manutenção do equilíbrio hidrológico da área, integrando as edificaçóes e vias de acesso ao ambiente físico e à sua biodiversidade.
\end{abstract}

Palavras-chave - Urbanismo sustentável: ambiente litorâneo: expansão de zonas urbanas.

Abstract - This work presents the results of a geo-scientific and multidisciplinary study, that was applied to littoral environments, and it's utility in terms of a proposal of Sustainable Urban development in the Zone of the Expansion the Aracaju city, capital of Sergipe State, Northeast of Brazil. Suggestions are presented in the current study that can lead to the preservation of coastal ecosystems, as well as the maintenance of the hydrologic balance of the area, integrating the constructions and ways of access to the physical environment and it's biodiversity.

Keywords - Sustainable urbanism, coastal environment, expansion of urban areas.

1 Rua Catumbi 507, apt 303. CEP 90870-270, Porto Alegre, Rio Grande do Sul, Brasil; e-mail: nina_0601@hotmail.com

2 Rua Catumbi 507, apt 303. CEP 90870-270, Porto Alegre, Rio Grande do Sul, Brasil; e-mail: gustavogarciageo@hotmail.com

3 Universidade Federal de Sergipe - UFS - Rua Rolando Vieira de Melo 245 apt 303, CEP 49036-190, Aracaju, Sergipe, Brasil; e-mail: garciageo@hotmail.com 


\section{1 - Introdução}

A ocupação humana dos ambientes naturais através da construção de áreas urbanas deve ser rigorosamente precedida de estudos de Impacto Ambiental. A Zona de Expansão da cidade de Aracaju (Fig. 1), no Estado de Sergipe (Brasil), vem sendo ocupada sem preocupação com as consequências, em termos de danos causados à flora e fauna como também, ao próprio meio físico (dunas costeiras e lagoas integradas ao ecossistema litorâneo) e sistemas hidrológicos (água subterrânea e lagoas). Muitos dos projetos que hoje estão implantados na área estudada comprometem a sustentabilidade ambiental da região, inviabilizando o escoamento de águas pluviais e subterrâneas, provocando a proliferação de agentes contaminantes humanos no lençol freático e das águas superficiais (lagoas e mangues).
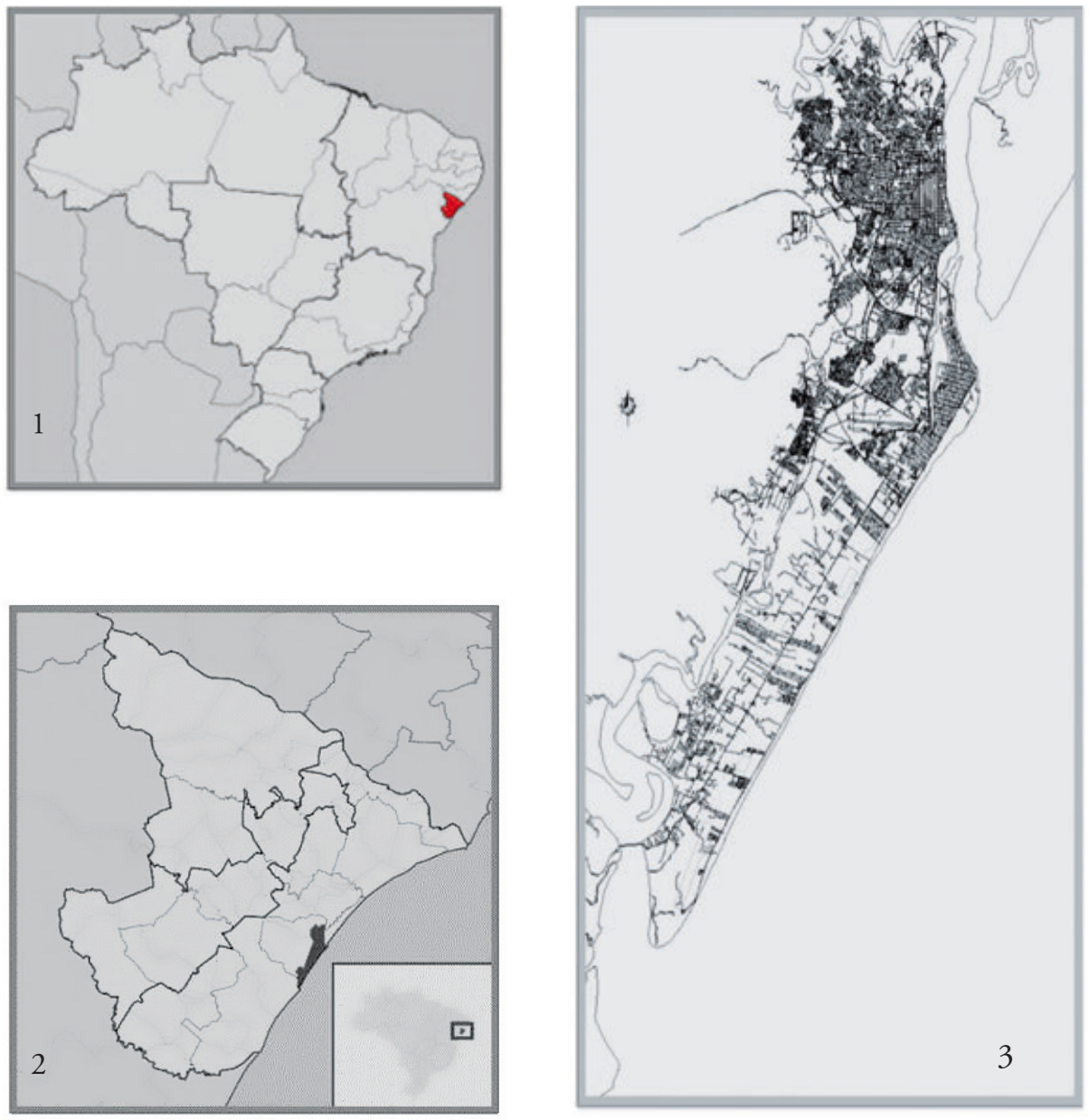

Fig. 1 - Contexto geográfico da cidade de Aracaju com destaque para as principais vias de conexão entre o centro e a zona de expansão (3), Sergipe (2), Brasil (1). 


\section{2 - Diagnóstico}

O "urbanismo geoambiental" é uma resposta para desenvolver o urbanismo em áreas de reconhecida fragilidade ambiental, como os ambientes litorâneos e zonas costeiras.

A busca de soluçôes que agreguem competências que permitam modificar o meio sem interferir drasticamente com a sustentabilidade é o grande desafio a ser vencido pela sociedade em tais contextos de ocupação territorial.

A proposta de "adequação urbana da cidade de Aracaju", Sergipe, Brasil, visa levar o desenvolvimento urbano sustentável à zona de expansáo, localizada em ambiente litorâneo. Neste trabalho, a zona de expansão é definida por $20,70 \mathrm{~km}^{2}$.

A área litorânea da cidade de Aracaju possui alta fragilidade ambiental, porque está situada em ambientes complexos formados por sedimentos de dunas e lagoas costeiras. Estes elementos são substrato para vegetação de restinga e de mangue, onde se estabelece um ecossistema litorâneo que deve ser mantido e integrado ao processo de urbanização.

\section{3 - Métodos}

O diagnóstico dos problemas causados pela urbanização sem sustentabilidade levou em consideração as relaçóes atuais do desenvolvimento urbano e os elementos naturais, em geral desconsiderados. Para tal, foram mapeados o estado atual de urbanização e os remanescentes de ambientes naturais em condiçóes de serem usados como pontos de referência para o Planejamento Sustentável. Estes elementos naturais foram analisados através de fotografias aéreas (fonte: ortofotocartas executadas pela Base Aerofotogrametria e Projetos S.A.), cartografia da distribuição e altura dos corpos de areia formando as dunas e os cordóes litorâneos de áreas lagunares e de mangue e, principalmente, a distribuição da flora e da fauna em cada eco-sistema identificado (Fig. 2).

Os conhecimentos geológico e biológico associado a cada um destes elementos naturais foram considerados na proposição de distribuição das sugestôes de edificaçóes e novas vias de acesso, visando assegurar a permanência dos ecossistemas e da manutenção dos corredores ecológicos entre os nichos ambientais. Outro importante aspecto considerado foi a dinâmica do fluxo hidrológico, tanto superficial como subterrâneo, a fim de manter o escoamento natural e evitar alagamentos mediante o represamento destes fluxos gerados pelas obras humanas, como hoje registrado sem o devido planejamento. 


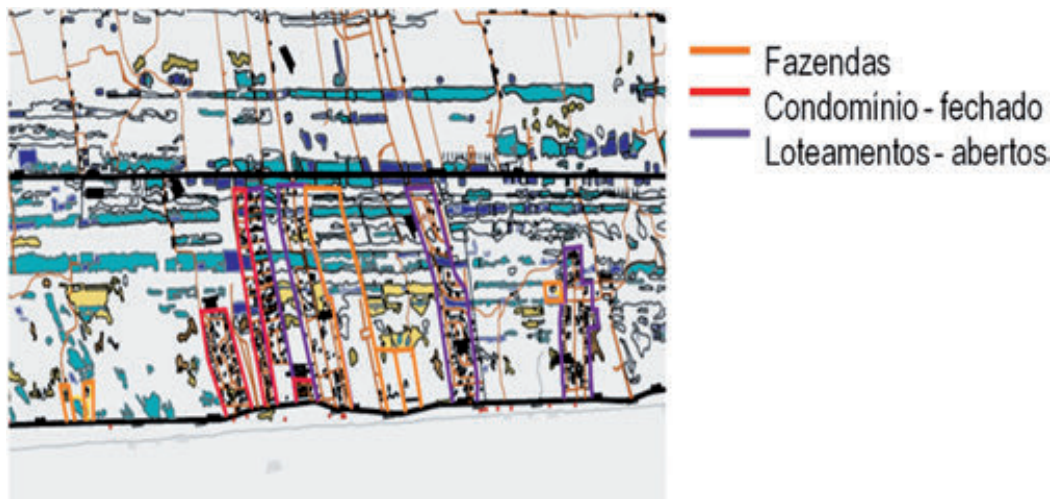

Fig. 2 - Mapeamento dos principais empreendimentos econômicos estabelecidos na zona de expansão de Aracaju e alvos das sugestóes de adequação apresentadas neste trabalho.

4 - Proposta de adequaçáo urbana - aracaju integrada ao meio físico

A Dra. Maria Augusta Vargas (VARGAS, 2009), manifesta-se da seguinte maneira com relação ao desenvolvimento urbano de Aracajú: "Planejada nos dias atuais, Aracaju seria vetada pela avaliação ambiental da legislação vigente. Contudo, a construção de uma cidade sustentável é possivvel e somente viável com a eliminação do entendimento da natureza intocável, que "congelaria" Aracaju, bem como do entendimento do ambiente natural indesejado, a ser conquistado e artificializado".

A região sul de Aracaju, em direção a fronteira com o estado da Bahia, apresenta grande potencial para investimentos que estão sendo planejados e desenvolvidos, portanto, é uma região que necessita com urgência da implementação de um plano de adequação urbana.

O impacto sócio econômico de uma estagnação do processo de desenvolvimento urbano para a cidade de Aracaju, neste momento seria táo catastrófico quanto os danos causados ao meio ambiente se este desenvolvimento não for sustentável.

\section{1 - Condomínios residenciais}

O conceito de "condomínios fechados" (Fig. 3) se confronta com o conceito de "cidades abertas", onde a distribuição das edificaçóes e obras viárias se desenvolve em conformidade harmônica com a topografia e os elementos naturais como dunas, lagoas naturais, vegetação de restinga ou vegetação de mangue. Estes elementos abrigam uma fauna e flora específica.

Os loteamentos adotam três princípios fundamentais: 1- o da observação do meio físico, biológico e hidrológico; 2- o da ocupação dos espaços de forma harmonizada com o meio físico; 3 - legislação ambiental brasileira (federal e estadual). Desta forma, os loteamentos propostos devem apresentar aspectos suficientemente irregulares que permitam a distribuição dos lotes de forma bem adequada ao terreno. 
Procurou-se utilizar os elementos naturais tais como dunas, lagoas e vegetaçáo como parte do paisagismo em cada loteamento, viabilizando assim, a preservaçáo dos elementos naturais e em alguns casos, a sua própria revitalização, cumprindo a determinação da legislação ambiental brasileira de forma harmoniosa.

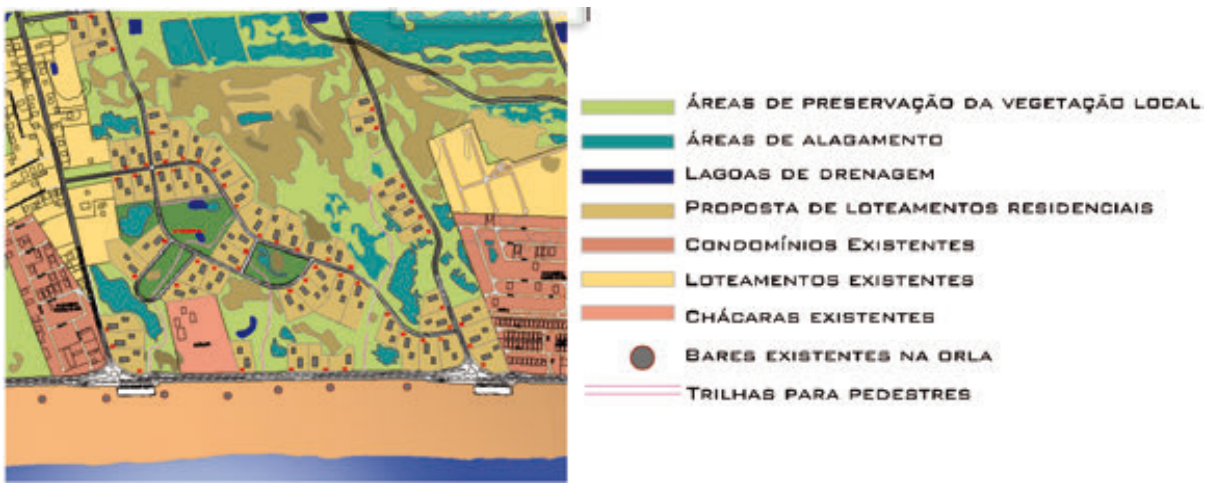

Fig. 3 - Modelo de condomínios de "chácaras" em ambiente urbano, assegurando a sustentabilidade ambiental para a zona de expansão da cidade de Aracaju. Área de preservação ambiental integrada com vias de acesso e pólos comerciais.

\section{2 - Obras viárias e pólos comerciais}

As obras viárias de acesso aos novos empreendimentos (Fig. 4), e mesmo aos já existentes, devem ser adequadas em conformidade com os princípios de sustentabilidade a serem considerados nos projetos de expansão da cidade.

Pólos comerciais devem ser planejados, em substituição às atuais edificaçôes, a partir da duplicação da Rodovia dos Naúfragos, que permite o acesso ao sul do estado, na fronteira com o estado da Bahia, que é um eixo de fluxo turístico intenso no verão e em grande parte do ano. 

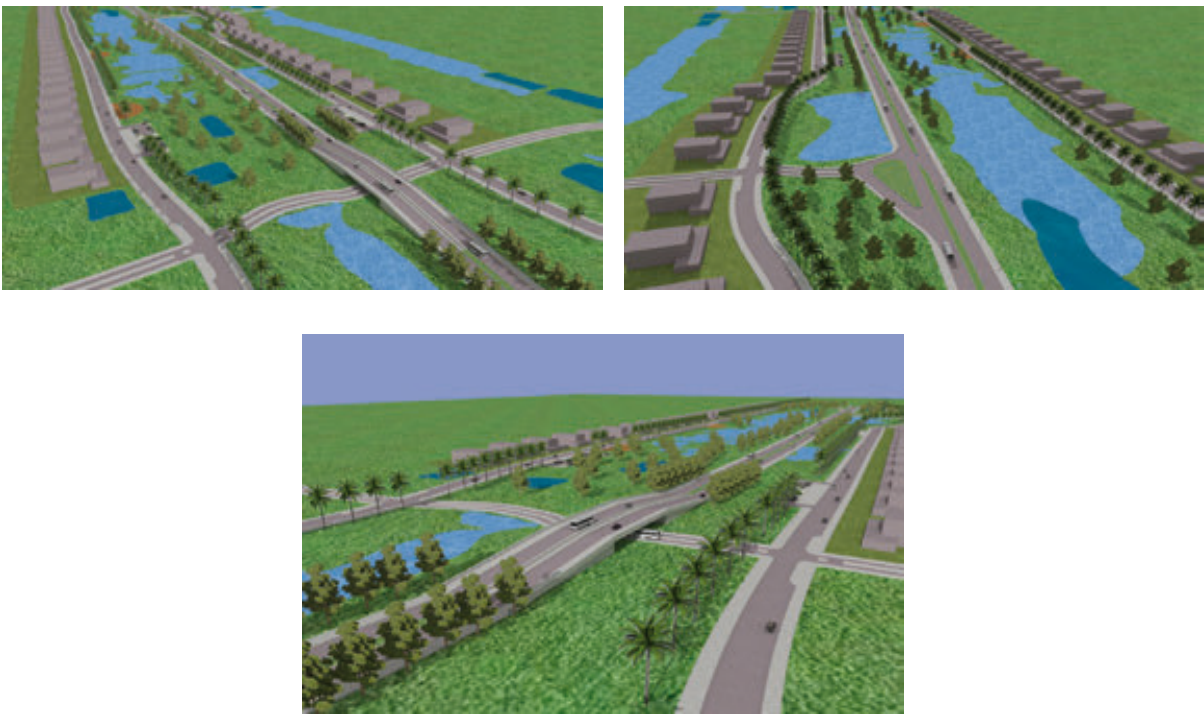

Fig. 4 - Rodovia dos Naúfragos. As vias de acesso às zonas edificadas devem ser planejadas a fim de permitir o fluxo de veículos e pedestres sem interferir no fluxo das águas (subterrâneas e superficiais).

\section{3 - Pólos turístico e cultural associados ao desenvolvimento científico e a educação ambiental}

No projeto de adequação urbana de Aracaju são sugeridos dois pólos, onde poderá ser desenvolvido o incentivo ao turismo e a cultura, com instalaçôes de apoio e comércio junto ao acesso a ponte sobre o Rio Vaza Barris (Fig. 5), e um pólo direcionado ao desenvolvimento científico e à educação ambiental, com passarelas e lunetas para observação do ecossistema existente junto a Foz do Rio Vaza Barris, nas proximidades do farol existente (Fig. 6). 

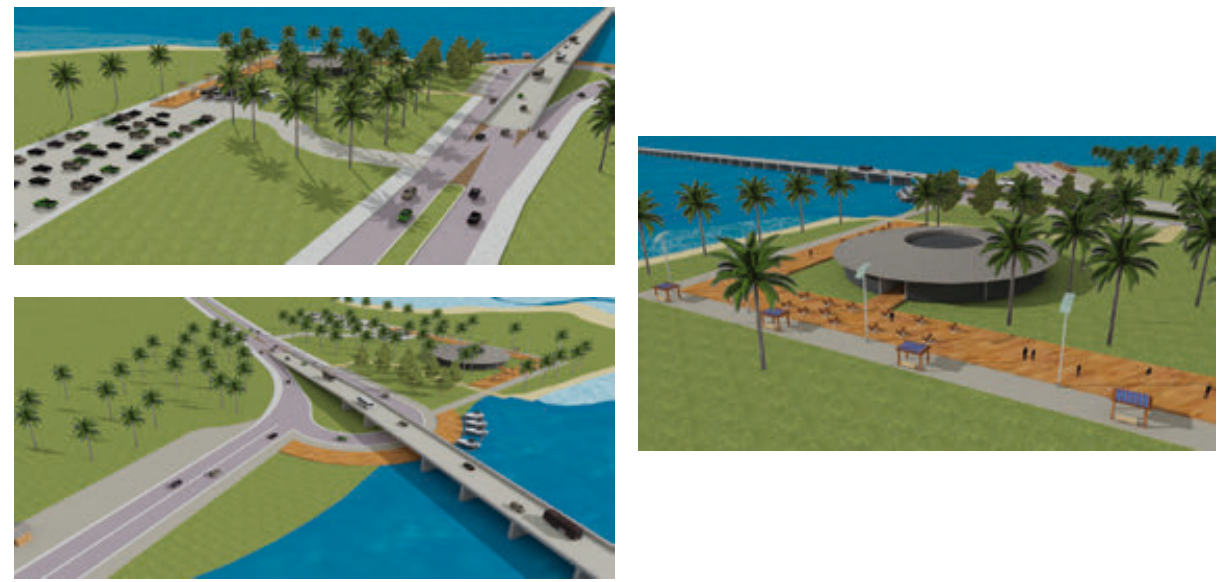

Fig. 5 - Pólo turístico e cultural sugerido para ser construído junto à ponte sobre o Rio Vaza Barris, ponto de recepção e passagem de quem trafega entre a cidade de Aracaju e o sul do estado de Sergipe, em direção a cidade de Salvador (Bahia) e vice-versa.
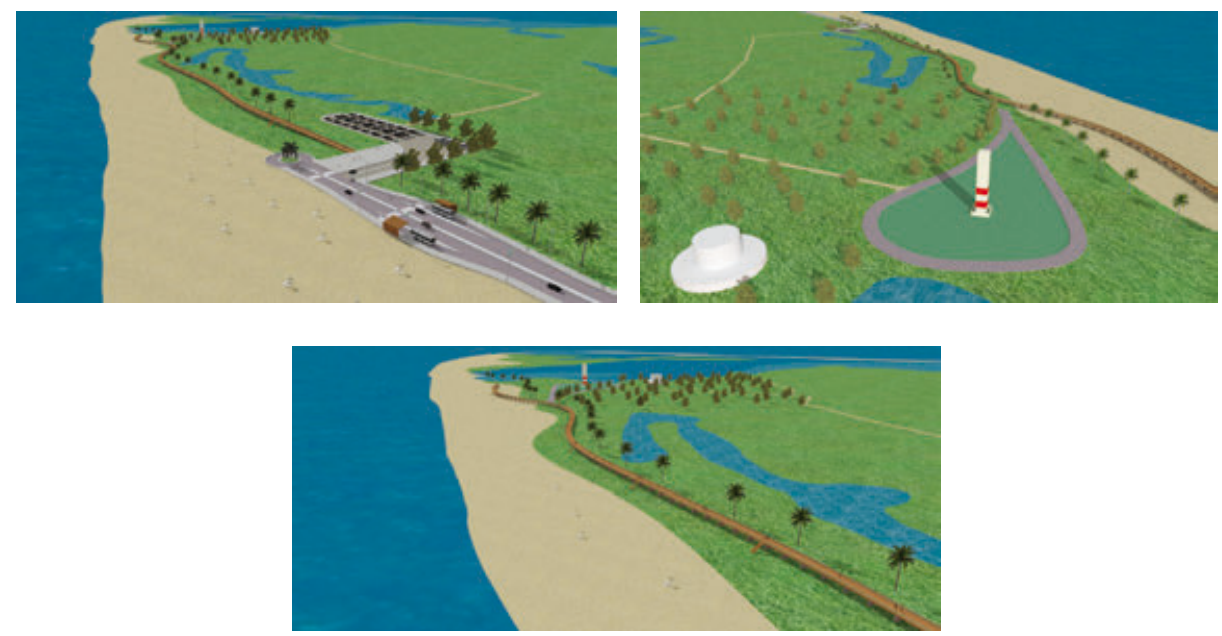

Fig. 6 - Pólo turístico e científico sugerido para ser construído nas imediaçôes da Foz do Rio Vaza Barris, em zona litorânea com um rico ecossistema. Possibilidade de vizualizaçấo de aspectos da fauna e flora e suas interatividades com o meio físico, constituído por campos de dunas e cordōes litorâneos, além de um ambiente praial que apresenta intensa ação erosiva gerada pelo desequilíbrio entre a disponibilidade de areia e a ação do mar.

\section{4 - Melhoria dos acessos e apoio aos banhistas}

Melhorias nas vias de acesso às praias e instalação de infraestruturas de apoio como a instalação de um comércio de praia e demais facilidades (estacionamentos, banheiros, chuveiros e arborização) (Fig. 7). 

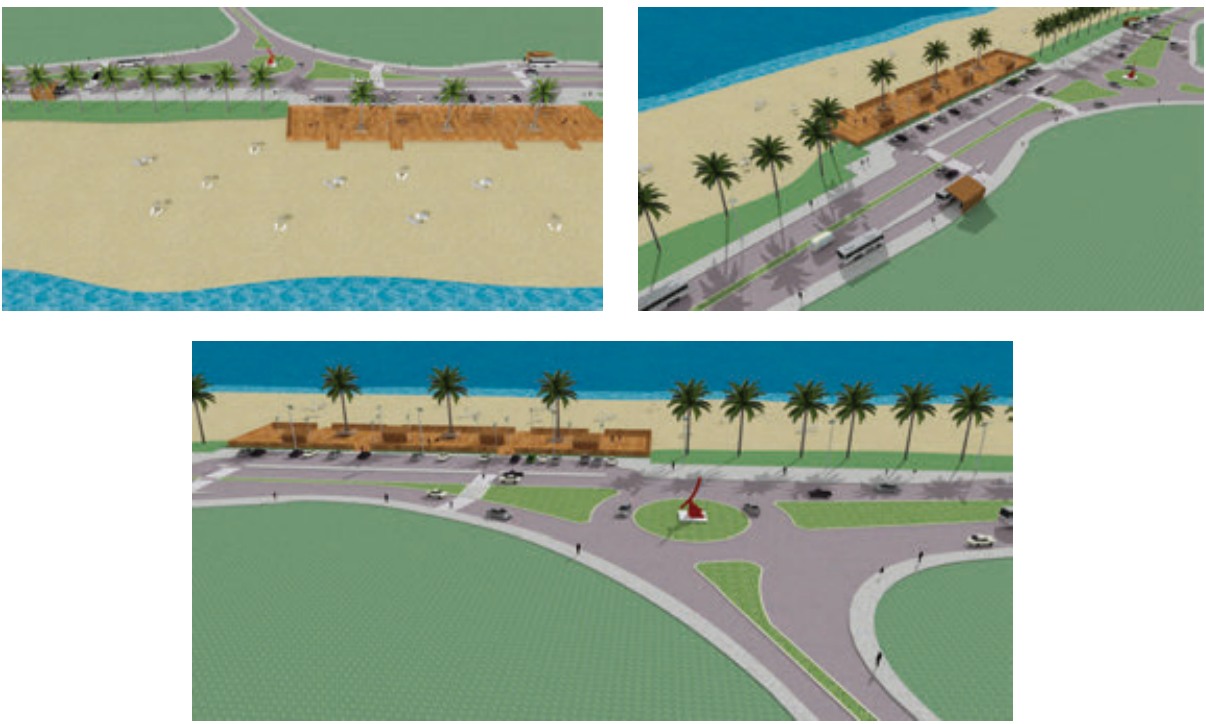

Fig. 7 - Os acessos e as facilidades instaladas para os banhistas têm a função de impedir a passagem de veículos para o ambiente de praia, evitando assim, a destruição dos campos de dunas e ecossistemas litorâneos.

\section{5 - Consideraçóes finais}

O projeto foi desenvolvido em um contexto de concomitância ao processo de expansão da cidade de Aracaju (Sergipe, Brasil). Neste contexto, as alternativas e sugestóes apresentadas correm o risco de não haver tempo para sua assimilação e aplicação, se considerarmos os trâmites políticos. No entanto, em situaçóes análogas as sugestóes deste trabalho para viabilizar o crescimento urbano sustentável podem servir de referência para o início da ocupação em outras localidades, onde o processo de urbanização ainda não tenha sido iniciado ou esteja em vias de implementação. A situação da expansão urbana da cidade de Aracaju requer maior velocidade nas decisóes relacionadas a preservação do meio-ambiente, consequentemente, buscar a recuperação dos ambientes já degradados e impedir a destruição onde ainda, os ecossistemas podem ser preservados.

\section{Referências Bibliográficas}

GARCIA, M. G. (2010) - Projeto de Adequaçâo Urbana Zona de Expansão da Cidade de Aracaju, Sergipe. Trabalho de Conclusão de Curso de Arquitetura e Urbanismo, Universidade do Vale do Rio dos Sinos UNISNOS, São Leopoldo, RS, Brasil.

VARGAS, M. A. M. \& NEVES, P. S. C. (2009) - Inventario de cada um dos oito territórios de Sergipe e elaboração de um Atlas da cultura sergipana. Relatório. Aracaju: UFS/ SEPLAN. 